\title{
Effects of widening during rolling on the subsequent recrystallization kinetics of copper
}

Lin, Fengxiang; Leffers, Torben; Juul Jensen, Dorte; Pantleon, Wolfgang

Published in:

Materials Science Forum

Link to article, DOI:

10.4028/www.scientific.net/MSF.753.285

Publication date:

2013

Document Version

Peer reviewed version

Link back to DTU Orbit

Citation (APA):

Lin, F., Leffers, T., Juul Jensen, D., \& Pantleon, W. (2013). Effects of widening during rolling on the subsequent recrystallization kinetics of copper. Materials Science Forum, 753, 285-288.

https://doi.org/10.4028/www.scientific.net/MSF.753.285

\section{General rights}

Copyright and moral rights for the publications made accessible in the public portal are retained by the authors and/or other copyright owners and it is a condition of accessing publications that users recognise and abide by the legal requirements associated with these rights.

- Users may download and print one copy of any publication from the public portal for the purpose of private study or research.

- You may not further distribute the material or use it for any profit-making activity or commercial gain

- You may freely distribute the URL identifying the publication in the public portal 


\title{
Effects of Widening during Rolling on the Subsequent Recrystallization Kinetics of Copper
}

\author{
F.X. Lin ${ }^{1, a}$, T. Leffers ${ }^{1, b}$, W. Pantleon ${ }^{2, c}$, D. Juul Jensen ${ }^{1, d}$ \\ ${ }^{1}$ Danish-Chinese Center for Nanometals, Materials Science and Advanced Characterization \\ Section, Department of Wind Energy, Technical University of Denmark, Risø Campus, 4000 \\ Roskilde, Denmark \\ ${ }^{2}$ Department of Mechanical Engineering, Section for Materials and Surface Engineering, Technical \\ University of Denmark, 2800 Kongens Lyngby, Denmark \\ alnfe@dtu.dk, btole@dtu.dk, 'pawo@dtu.dk, ddoje@dtu.dk
}

Keywords: copper, rolling, widening, recrystallization, cube texture

\begin{abstract}
Recrystallization kinetics in copper cold-rolled to $90 \%$ reduction, with and without significant widening, was investigated by electron backscatter diffraction. It was found that the recrystallization process was slightly retarded, and the development of the cube recrystallization texture was largely inhibited in the widening sample. Cube grains were observed to have a growth advantage by a factor of 2 in the non-widening sample, while this growth advantage was not observed in the widening sample. The development of the cube texture in the two samples is discussed.
\end{abstract}

\section{Introduction}

The recrystallization process, including recrystallization kinetics and microstructural evolution, in cold-rolled face centered cubic metals has been widely investigated. In particular, the formation of a strong cube recrystallization texture has been discussed intensively, and has been related to oriented nucleation and/or oriented growth. Several parameters, such as initial grain size, deformation strain and material purity have been found to affect the cube texture development [15]. It is normally assumed that rolling is equivalent to plane strain compression, i.e. that there is no change in the sample dimension along the transverse direction (TD). However, when the initial size of the sample along TD is small, significant widening during rolling is observed [6]. In aluminium, it has been recognized that significant widening strongly inhibits the development of the cube texture during recrystallization [7]. On the other hand the complete elimination of widening as in channel-die compression reduces the strength of the cube recrystallization texture [8]. The objective of the present paper is to compare two otherwise identical samples which have been rolled with and without significant widening, and to investigate the recrystallization kinetics in these two samples.

\section{Experimental}

The initial material was commercial oxygen free high conductivity copper with an average grain size of $22 \mu \mathrm{m}$. The initial texture was very weak. Further details of the material can be found in [9]. Specimens with a starting thickness and width $\left(\mathrm{w}_{0}\right)$ of $5.2 \times 44.1 \mathrm{~mm}^{2}$ and $9.3 \times 13.4 \mathrm{~mm}^{2}$, respectively, were rolled homogeneously to $90 \%$ reduction. The relative widening was calculated as $\left(w-w_{0}\right) / w_{0}$, where $\mathrm{w}$ is the sample width at $90 \%$ reduction. The relative widening was $8.4 \%$ and $38.6 \%$ in the two samples respectively. The amount of widening in the first sample is normal for a rolled sample (e.g. [8]), while that in the second sample is significant, and cannot be ignored. These two samples are termed NW (non-widening, or better normal widening) and W (widening) samples in the following. Both samples were annealed isothermally at $150{ }^{\circ} \mathrm{C}$ for various time periods. The longitudinal planes in the center of the specimens were characterized by electron backscatter diffraction (EBSD) with a step size of $1 \mu \mathrm{m}$. Recrystallized grains were identified automatically 
from the EBSD data by a program developed for this purpose, the DRG program [10]. A large density of twin boundaries developed during recrystallization, and these twin boundaries were considered as normal high angle boundaries for defining recrystallized grains, which means that twin parts of a grain were treated as separated grains.

\section{Results and discussion}

The volume fractions of the main components of the deformation textures of the two samples are summarized in Tab. 1 . In both samples, the $\mathrm{S}$ texture component is the dominant component, but the $\mathrm{S}$ component is stronger in the NW sample. The volume fractions of copper and brass texture component are similar in the two samples. Also in both samples, there is a weak cube texture component.

The evolution of the volume fraction of recrystallized material $\left(\mathrm{V}_{\mathrm{V}}\right)$ is plotted in Fig. 1a as a function of annealing time. The recrystallization process is slightly retarded in the $\mathrm{W}$ sample. The same data are plotted in the form of $-\ln \left(1-V_{V}\right)$ against annealing time on a log-log scale in Fig. 1b. A linear relationship is observed for $V_{V}$ less than $60 \%$, with slopes equal to 1.38 and 1.83 in the NW and W sample, respectively. At longer annealing time, the slopes decrease. The data do not follow the simple JMAK relationship $V_{V}=1-\exp \left(-k t^{n}\right)$ any longer. A similar result has been observed for copper rolled to $92 \%$ reduction previously [11].

The textures after recrystallization in the two samples are also listed in Tab. 1 . The cube texture component becomes the dominant texture component in the NW sample, with a volume fraction of about $50 \%$. In the $\mathrm{W}$ sample, the volume fraction of the cube component is only $13 \%$ after recrystallization.
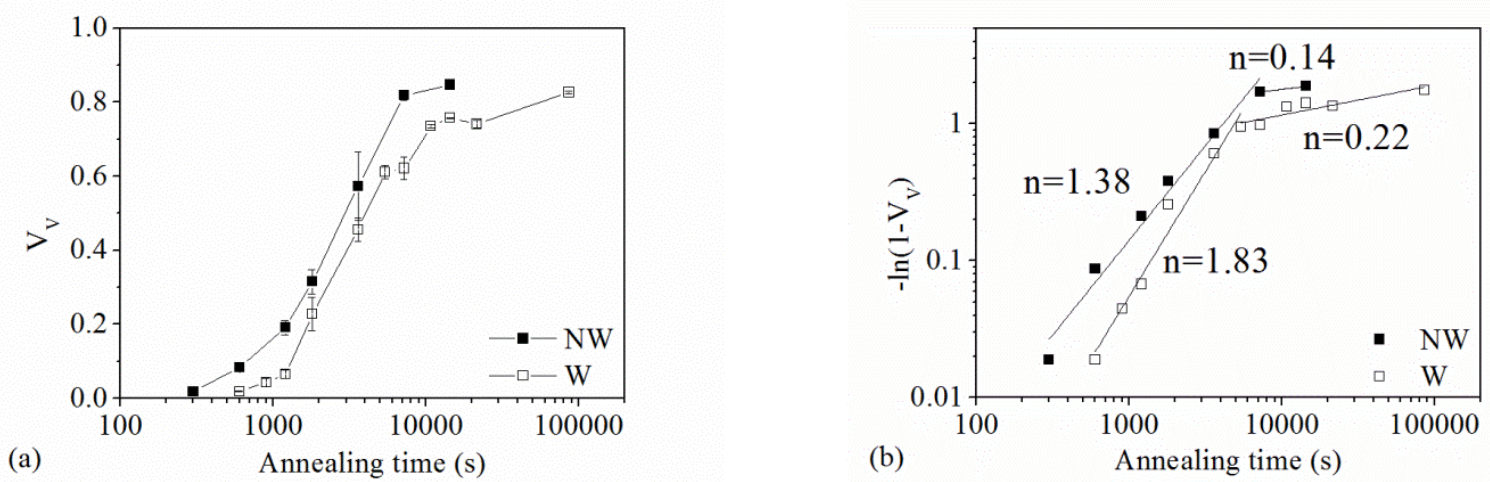

Fig. 1. a) Evolution of the recrystallized volume fraction as a function of annealing time and b) the same data as in a) plotted as $-\ln \left(1-V_{V}\right)$ against annealing time on a log-log scale.

Tab. 1 Volume fractions of different texture components of the deformation and recrystallization texture in the NW and W samples. Texture components are defined using a $15^{\circ}$ deviation to the ideal orientations. It has to be noted that the $\mathrm{NW}$ and $\mathrm{W}$ samples were only $85 \%$ and $83 \%$ recrystallized after the longest annealing times used here. The recrystallized volume fraction of each texture component $\mathrm{V}_{\mathrm{Vi} \text {,cor }}$ are thus calculated as $\mathrm{V}_{\mathrm{Vi} \text {,cor }}=\mathrm{V}_{\mathrm{Vi} \text {,measured }} / \mathrm{V}_{\mathrm{V}}$.

\begin{tabular}{lllllll}
\hline Sample & State & cube & copper & brass & S & other \\
\hline \multirow{2}{*}{ NW } & Deformation & $1 \%$ & $14 \%$ & $22 \%$ & $40 \%$ & $22 \%$ \\
\cline { 2 - 7 } & Recrystallization & $48 \%$ & $1 \%$ & $3 \%$ & $15 \%$ & $33 \%$ \\
\hline \multirow{2}{*}{ W } & Deformation & $1 \%$ & $13 \%$ & $19 \%$ & $31 \%$ & $37 \%$ \\
\cline { 2 - 7 } & Recrystallization & $13 \%$ & $4 \%$ & $5 \%$ & $20 \%$ & $58 \%$ \\
\hline
\end{tabular}


The growth rates of cube and noncube grains in the NW and W samples are determined using a methodology first suggested by Cahn and Hagel [12] and later extended to include analyses of growth rates as a function of orientations [13] (see Fig. 2). The growth rates decrease with time as $G=G_{0} t^{-r}$, with $\mathrm{r}$ around 1 for both cube and noncube grains, in both samples. The cube grains have a higher growth rate (by a factor of about 2) in the NW sample. In this sample, the average grain size of cube at the end of recrystallization is $11 \mu \mathrm{m}$, which is about twice that of noncube grains $(6 \mu \mathrm{m})$. The cube grains, however, do not show an obvious growth advantage compared with noncube grains in the $\mathrm{W}$ sample. It has to be noted that the average grain size of cube grains $(7 \mu \mathrm{m})$ is slightly larger than that of noncube grains $(6 \mu \mathrm{m})$ at the end of recrystallization in the W sample. However, the average size of cube grain is already $7 \mu \mathrm{m}$ at the beginning of recrystallization, and with longer annealing times, the average size does not increase because continuously many small new cube grains form, some of which by twinning of noncube grains.
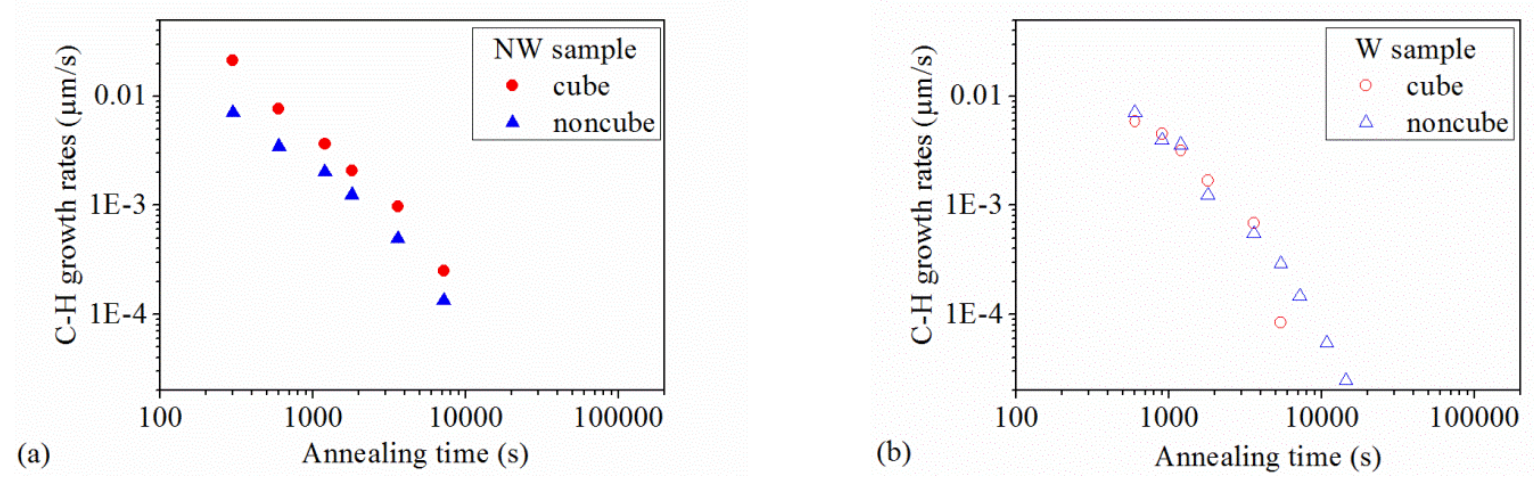

Fig. 2. Average Cahn-Hagel growth rates of cube and noncube recrystallized grains in a) the NW sample and $\mathrm{b}$ ) the $\mathrm{W}$ sample. For a given texture group $i$, the average growth rate is calculated as $\langle\mathrm{G}\rangle_{\mathrm{i}}=\left(\mathrm{dV} \mathrm{V}_{\mathrm{V}} / \mathrm{dt}\right)_{\mathrm{i}} / \mathrm{S}_{\mathrm{V}, \mathrm{i}}$, where the $\mathrm{S}_{\mathrm{V}, \mathrm{i}}$ is the volume density of surface area between recrystallized grains of the ith texture component and the surrounding deformed matrix.

The less developed cube recrystallization texture in the $\mathrm{W}$ sample can, at least partly, be attributed to the absence of a growth advantage of cube grains during recrystallization. In the NW sample, it was found that a small number of cube grains have very large grain sizes at the end of recrystallization, which contribute a lot to the cube recrystallization texture and to the larger average cube size. These huge cube grains are termed supercube grains [14]. It has been suggested [14] that the growth advantage of cube grains may originate from these supercube grains, while other cube grains grow at a similar rate as noncube grains. In the $\mathrm{W}$ sample, there are a few large cube grains, but their size advantage compared with the noncube grains is not as obvious as the supercube grains in the NW sample. It is interesting to note, however, that cube grains do have larger average size from the beginning of recrystallization in the $\mathrm{W}$ sample. A few cube grains with a size as large as $30 \mu \mathrm{m}$ are observed in the $\mathrm{W}$ sample after 10 minutes annealing. However, it seems that these relatively large cube grains observed at the beginning of recrystallization do not continue to grow at a high growth rate to reach a huge final size. The difference in deformation texture may partly explain this observation, since the rolling texture is weaker in the $\mathrm{W}$ sample. However, the growth of recrystallized grains is complex [15], and more detailed investigations, especially in-situ investigations, are underway to further the understanding of the development of supercube grains.

\section{Conclusions}

Specimens were cut to two different dimensions and cold-rolled to $90 \%$ thickness reduction. Significant widening was developed in one of the samples. The deformation texture was slightly weaker in the widening sample, while the recrystallized textures were significantly different: a 
strong cube texture developed only in the non-widening sample. The recrystallization process was slightly retarded in the widening sample. The recrystallized cube grains were found to have a growth advantage by a factor of 2 in the non-widening sample, which was not observed in the widening sample. This growth advantage of cube grains was related to the appearance of supercube grains in the non-widening sample. They are only a minor fraction of the cube grains, but they grow with a higher growth rate and reach a very large final size.

\section{Acknowledgement}

The authors gratefully acknowledge the support from the Danish National Research Foundation and the National Natural Science Foundation of China (Grant No. 51261130091) to the DanishChinese Center for Nanometals, within which this work was performed.

\section{References}

[1] G. Wassermann and J. Grewen, Texturen Metallischer Werkstoffe, Springer-Verlag, Berlin, 1962, pp. 307-326.

[2] A.A. Ridha and W.B. Hutchinson, Recrystallization mechanisms and the origin of cube texture in copper. Acta Metall. 30 (1982) 1929-1939.

[3] D. Juul Jensen and J.K. Kjems, Apparatus for dynamical texture measurements by neutron diffraction using a position sensitive-detector. Textures Microstruct. 5 (1983) 239-251.

[4] W.B. Hutchinson, S. Jonsson and L. Ryde, On the kinetics of recrystallization in cold worked metals. Script. Metall. 23 (1989) 671-676.

[5] C.T. Necker, R.D. Doherty and A.D. Rollett, Quantitative measurement of the development of recrystallization texture in OFE copper. Textures Microstruct. 14-18 (1991) 635-640.

[6] H.J. Bunge, Some applications of the Taylor theory of polycrystals plasticity. Kristall. Technik. 5 (1970) 145-175.

[7] W. Mao, Influence of widening on the rolling and recrystallization texture in high purity Al with initial cube texture. Chin. J. Met. Sci.Technol. 6 (1990) 325-332.

[8] H. Hammelrath, J.F. Butler Jr, D. Juul Jensen, T. Leffers, H. Hu and K. Lucke, An ODF study of the deformation and recrystallization textures of rolled and channel-die compressed high purity copper. Textures Microstruct. 13, (1991) 165-187.

[9] F.X. Lin, W. Pantleon, T. Leffers and D. Juul Jensen, Effects of initial parameters on the development of cube texture during recrystallization of copper. Mater. Sci. Forum 702-703 (2012) 398-401.

[10] G.L. Wu and D. Juul Jensen, Automatic determination of recrystallization parameters based on EBSD mapping. Mater. Charact. 59 (2008) 794-800.

[11] R.A. Vandermeer and D. Juul Jensen, Quantifying recrystallization nucleation and growth kinetics of cold-worked copper by microstructural analysis. Metall. Mater. Trans. 26A (1995) 22272235.

[12] J.W. Cahn and W.C. Hagel, Theory of the pearlite reaction. in: V.F. Zackay and H.I. Aaronson (Eds.), Decomposition of Austenite by Diffusional Processen, Interscience, New York, 1962, pp. 131-196.

[13] D. Juul Jensen, Growth of nuclei with different crystallographic orientations during recrystallization. Script. Metall. Mater. 27 (1992) 533-538.

[14] F.X. Lin, Y.B. Zhang, W. Pantleon and D. Juul Jensen, Recrystallization kinetics of copper cold rolled to $90 \%$ reduction with different initial grain sizes. to be submitted.

[15] Y.B. Zhang, A. Godfrey, Q. Liu, W. Liu and D. Juul Jensen, Analysis of the growth of individual grains during recrystallization in pure nickel. Acta Mater. 57 (2009) 2631-2639. 